\title{
Qualidade das águas cinza tratada com fitorremediação em unidades de produção agrícola
}

\section{Quality of Gray water treated with phytoremediation in agricultural production units}

\author{
Verena S. Baracuhy ${ }^{1}$, Jórgerson P. G. Pereira ${ }^{2}$, Aline C. Ferreira ${ }^{3}$, Viviane F. Silva ${ }^{4}$, Nicola S. ${ }^{5}$
}

Resumo- A irrigação é uma atividade que necessita de grande quantidade de água, o tratamento de águas cinzas provenientes de uma lavanderia pública em regiões semiáridas para reuso passa a ser uma alternativa de sobrevivência neste ambiente e favorável no desenvolvimento econômico sustentável. Nesse contexto, a pesquisa foi realizada no distrito de Ribeira no município de Cabaceiras - PB objetivando-se avaliar a qualidade da água cinza tratada com fitorremediação nas unidades de produção agrícola. Foram realizados dois tratamentos com(Tanque 2) e sem fitorremediação(Tanque 1), a cultura utilizada foi o capim elefante roxo. Foram coletadas amostras mensais e analisadas os seguintes parâmetros fisicoquimicos: Turbidez, pH, Condutividade elétrica (Ce), Demanda Quimica de Oxigenio(DQO) e Fostoro Total. Para a turbidez os valores dos tratamentos foram acima de 1.000 UNT. Na demanda química de oxigênio, o valor mínimo foi de $311 \mathrm{mg} / \mathrm{L}$ (setembro) e máximo de $438 \mathrm{mg} / \mathrm{L}$ (outubro) no tanque 2 em contrapartida no tanque 1 o valor mínimo foi de $354 \mathrm{mg} / \mathrm{L}$ (setembro) e máximo de $618 \mathrm{mg} / \mathrm{L}$ (outubro). O tratamento com fitorremediação teve uma maior eficiência na redução de DQO.

Palavras - chave: capim elefante roxo, reuso, irrigação.

Abstract- Irrigation is an activity that requires large amounts of water, the treatment of greywater from a public laundry in semi-arid regions for reuse becomes a means of survival in this environment and conducive to sustainable economic development. In this context, the research was conducted in the district of the municipality of Ribeira Cabaceiras - PB aiming to evaluate the quality of gray water treated with phytoremediation in agricultural production units. Two treatments (Tank 2) and without phytoremediation (Tank 1) were performed, the culture used was purple elephant grass. Monthly samples were collected and analyzed the following physicochemical parameters: turbidity, $\mathrm{pH}$, electrical conductivity (Ce), Chemical Oxygen Demand (COD) and Total Fostoro. For the turbidity values of the treatments were over 1,000 UNT. In chemical oxygen demand, the minimum value was $311 \mathrm{mg} / \mathrm{L}$ (in September) and a maximum of 438mg / L (October) in tank 2 however in tank 1 the minimum value was $354 \mathrm{mg} / \mathrm{L}$ (in September) and a maximum of $618 \mathrm{mg} / \mathrm{L}$ (October). Treatment with phytoremediation has a higher efficiency of COD reduction.

Keywords: purple elephant grass, reuse, irrigation.

\footnotetext{
*Autor para correspondência

Recebido em aceito em 18/03/2015; aprovado em 21//03/2015

${ }^{1}$ Mestre em Recursos Naturais pela UFCG. Email: verena_schiel@yahoo.com

${ }_{2 ; 3}$ Professores da Universidade Federal de Campina Grande (UFCG). Email: alinecfx@yahoo.com.br.

${ }^{4}$ Mestranda em Engenharia Agrícola na Universidade Federal de Campina Grande - UFCG. Email: flordeformosur@hotmail.com; linebrito@homtail.com.

End.: Av. Aprígio Veloso, 882, Bodocongó, CEP: 58109-970, Campina Grande, PB. Tel.: (83) 2101-1491

${ }^{5}$ Professora da Universidade Federal Rural de Pernambuco (UFRPE). Email: nschiel@yahoo.com
} 


\section{INTRODUÇÃO}

A água é um recurso natural que apesar de abundante na superfície do planeta de acordo com Baird \& Cann (2011), $97 \%$ da água do mundo estão nos oceanos e mares, sendo assim, indisponível para o consumo humano e para ser utilizada na agricultura. O Brasil possui $13,7 \%$ do total de água doce do mundo. Desse total, $70 \%$ estão localizadas na região norte, mais precisamente na bacia amazônica, os outros $30 \%$ estão distribuídos entre as demais regiões. O Nordeste é a região mais afetada pela escassez de água, tendo como complicador o clima que não favorece a precipitação de chuvas periódicas (HARTMANN, 2010).

As discussões sobre a gestão hídrica e sustentabilidade bem como o uso racional da água tem gerado complexos planejamentos sobre a melhor forma de aproveitamento, já que a região nordestina apresenta índices pluviométricos irregulares, escassez de água, sendo um problema corriqueiro a ser solucionado. Para Salati et al. (2002), as ações devem ser fundamentadas em identificar, explorar e desenvolver iniciativas eficientes, que promovam a sustentabilidade e conservação da água e seu uso de forma adequada.

A Política Nacional de Recursos Hídricos (Lei 9.433/97) cita que em situações de escassez, o uso prioritário dos recursos hídricos é o consumo humano e animal, e que a gestão dos recursos hídricos deve sempre proporcionar o uso múltiplo das águas. De acordo com a Agência Nacional de Águas ANA (2011) a água, em função de suas qualidades e quantidades, propicia vários tipos de uso, isto é, múltiplos usos. O uso dos recursos hídricos por cada setor pode ser classificado como consuntivo e não consuntivo.

Para Domingos \& Oliveira (2008) a escassez de água potável, está se tornando um fator limitante para o desenvolvimento urbano, industrial e agrícola em determinados locais. Azevedo (2012) evidência a importância do gerenciamento hídrico para o semiárido nordestino, devido a períodos de seca prolongados, necessitando de projetos de implantação de gerenciamento hídrico. Nas microrregiões paraibanas necessita-se levantar discussões e reflexões sobre essa questão, agregando população e governo com o intuito de desenvolvimento, tendo em vista soluções, perspectivas e projetos eficientes na gestão da água (CEDRAZ, 2002).

$\mathrm{O}$ tratamento de água secundária torna-se uma alternativa para a irrigação na agricultura no semiárido. O reuso de água secundária tratada é uma maneira de reduzir a poluição do meio ambiente como rios e solo, proporcionando disponibilidade de água para irrigação de culturas forrageiras possibilitando um desenvolvimento econômico na região semiárida. A utilização das águas residuárias tratadas na agricultura é importante não apenas por servir como fonte extra de água, mas também de nutrientes para as culturas (SANDRI et al., 2007). A reutilização de efluentes tratados e/ou parcialmente tratados na irrigação de culturas agrícolas e/ou florestas, ao invés de descarregá-los nos cursos d'água, tem sido uma alternativa popular de rápida expansão nos últimos anos principalmente nas regiões áridas e semiárido.
A unidade de produção agrícola instalada no distrito de Ribeira/PB caracteriza-se como uma estação de tratamento, pois tem como base o processo de fitorremediação. Este processo é uma técnica de descontaminação, na qual se utilizam plantas para remover poluentes do ambiente ou transformá-los em formas menos perigosas para os seres vivos. O impacto ambiental e os custos de implementação são inferiores àqueles dos métodos físicos e químicos, além de ser uma técnica de fácil implementação (PILON-SMITS, 2005).

Nesse contexto, o presente trabalho foi realizado objetivando-se avaliar os parâmetros fisicoquimicos da água cinza tratada com fitorremediação nas unidades de produção agrícola no semiárido Paraibano.

\section{MATERIAL E METODOS}

A pesquisa foi desenvolvida em uma Unidade de Produção Agrícola Controlada (UPAC) instalada no distrito de Ribeira (S $7^{\circ} 25^{\prime}$ e W $36^{\circ} 21^{\prime}$ ), no município de Cabaceiras que se situa no semiárido do cariri paraibano, com 2.500 habitantes e distam 183,8 km de João Pessoa, capital do Estado da Paraíba e $78 \mathrm{~km}$ de Campina Grande. Apresenta as seguintes coordenadas geográficas: $7^{\circ} 29^{\prime} 21^{\prime \prime} \mathrm{Sul}, 36^{\circ} 17^{\prime}$ $18^{\prime \prime}$ Oeste e uma altitude média de $400 \mathrm{~m}$ acima do nível do mar. Estas coordenadas estão inseridas na unidade geoambiental do Planalto da Borborema, formada por maciços e outeiros altos, com altitude variando entre 650 a 1.000 metros (AESA, 2013; FERREIRA, 2013).

A Unidade de Produção Agrícola Controlada (UPAC) foi uma adaptação do modelo desenvolvido por Galbiati (2009) que se diferenciou na impermeabilização de cada unidade. Esta foi construída com oito subunidades ("tanques") de produção impermeáveis compostas de lonas plásticas e pneus velhos com volume de $6 \mathrm{~m}^{3}$. O efluente proveniente da lavanderia publica é conduzido através da tubulação PVC de $100 \mathrm{~mm}$ até uma caixa de água de 500 litros para posterior distribuição às unidades experimentais. O reservatório foi posicionado de modo que todo efluente seja distribuído às subunidades por gravidade.

A unidade de produção do presente estudo apresenta oito tanques, ou seja, oito subunidades (Figura 1) com dimensões de: $3,0 \times 2,0 \times 1,0 \mathrm{~m}$ o equivalente a aproximadamente $6 \mathrm{~m}^{3}$.

As quatro primeiras subunidades correspondendo a $\mathrm{T} 1 \mathrm{a}$; T1b; T1c e T1d respectivamente não apresentam o cultivo de capim elefante, ou seja sem fitorremediação, enquanto que as demais subunidades T2a; T2b; T2c e T2d cultivam quantidades semelhantes do capim com um espaçamento equivalente a $40 \mathrm{~cm}$ entre cada cultura. A finalidade da ausência de cultivo nas quatro subunidades foi para verificação da influência do processo de fitorremediação.

Foram realizados amostragens mensais, num período de 4 meses, no Laboratorio de Referência em Dessalinização (LABDES) da Universidade Federal de Campina Grande, analisando os seguintes parâmetros físicoquimicos:Turbidez, $\mathrm{pH}$, Condutividade elétrica (Ce), Demanda Quimica de Oxigenio(DQO) e Fostoro Total.. 

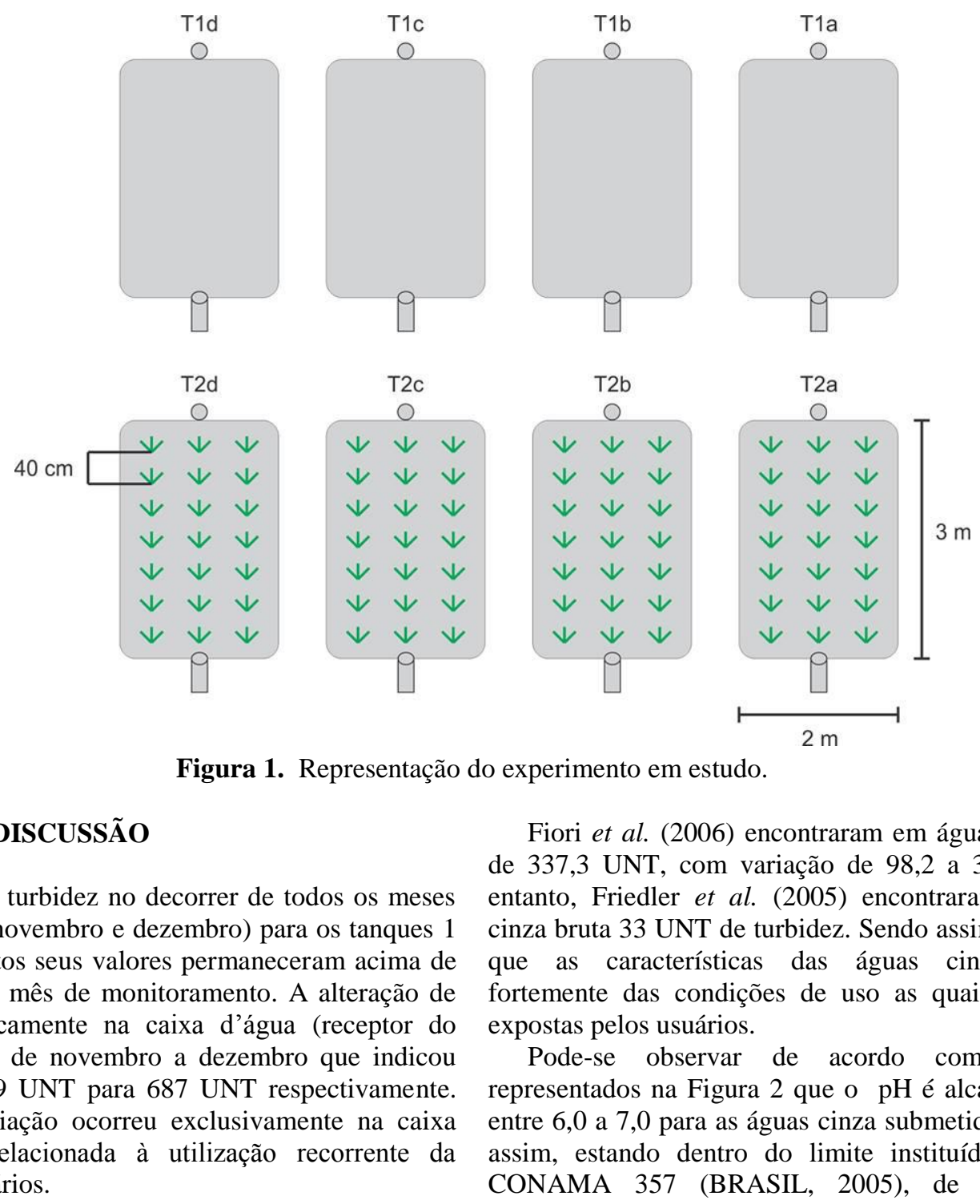

\section{RESULTADOS E DISCUSSÃO}

Para o parâmetro turbidez no decorrer de todos os meses (setembro, outubro, novembro e dezembro) para os tanques 1 e 2 não foram distintos seus valores permaneceram acima de 1.000 UNT em cada mês de monitoramento. A alteração de valores ocorreu unicamente na caixa d'água (receptor do efluente) no período de novembro a dezembro que indicou uma variação de 169 UNT para 687 UNT respectivamente. Possivelmente a variação ocorreu exclusivamente na caixa d'água por estar relacionada à utilização recorrente da lavanderia pelos usuários.
Fiori et al. (2006) encontraram em águas cinzas média de 337,3 UNT, com variação de 98,2 a 383,3 UNT. No entanto, Friedler et al. (2005) encontraram para a água cinza bruta 33 UNT de turbidez. Sendo assim, comprova-se que as características das águas cinzas dependem fortemente das condições de uso as quais as águas são expostas pelos usuários.

Pode-se observar de acordo com os resultados representados na Figura 2 que o pH é alcalino com valores entre 6,0 a 7,0 para as águas cinza submetida ao tratamento e assim, estando dentro do limite instituído pela resolução CONAMA 357 (BRASIL, 2005), de 5,0 a 9,0 para lançamento de efluentes.

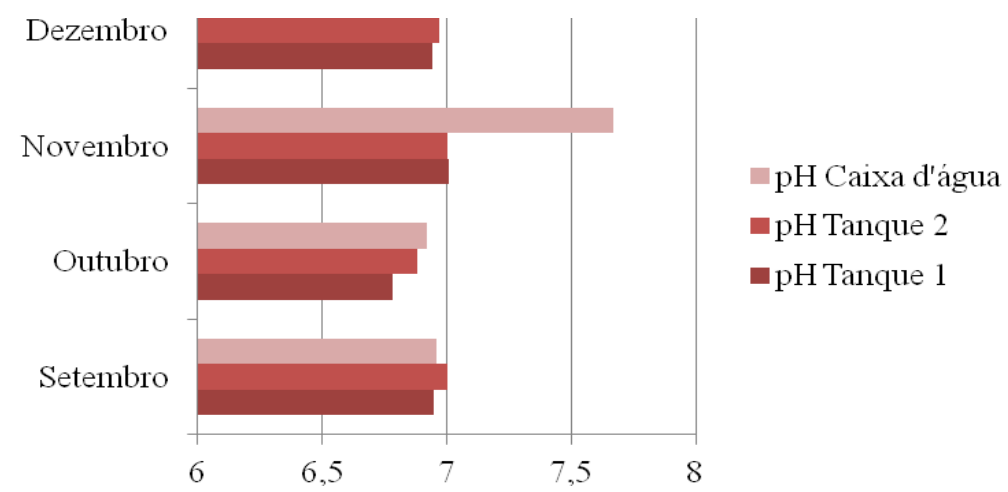

Figura 2. Monitoramento do pH nos Tratamentos sem fitorremediação (Tanque 1) e com fitorremediação (Tanque 2).

Eriksson et al. (2002), em trabalhos com caracterização de águas de máquina de lavar e tanques de lavagem de roupas, encontrou $\mathrm{pH}$ alcalino nas amostras depois da lavagem, os mesmos afirmam que quanto aos parâmetros químicos, o pH na água cinza depende do $\mathrm{pH}$ da água de abastecimento.

De acordo com Ferreira (2013) as leituras observadas em sua pesquisa, ao final do experimento na mesma lavanderia, o $\mathrm{pH}$ variou de 7,05 a 7,36 das águas cinzas efluentes. A utilização de sabão em pó, amaciantes e alguns produtos químicos podem contribuir à elevação do nível do mesmo. Com relação à cultura, Lopes (2004) afirma que o capim elefante não tolera baixo $\mathrm{pH}$ no solo.

Segundo Ferreira (2013) a condutividade elétrica em águas, seja ela cinza ou negra, expressa a concentração de íons presentes, ou, mais precisamente, de íons em solução. Como a condutividade elétrica em uma solução é 
proporcional à concentração iônica presente no meio (passagem de corrente elétrica num meio ionizado), existe relação de proporcionalidade entre o valor da condutividade elétrica e a concentração iônica.
Na figura 3 encontram-se os resultados da condutividade elétrica que ficou em entre os valores de 2.700 a 3.850 $\mu \mathrm{S} / \mathrm{cm}$. Niremberg \& Reis (2010) obtiveram a média de 594,0 $\mu \mathrm{S} / \mathrm{cm}$, valor abaixo ao detectado no presente trabalho.

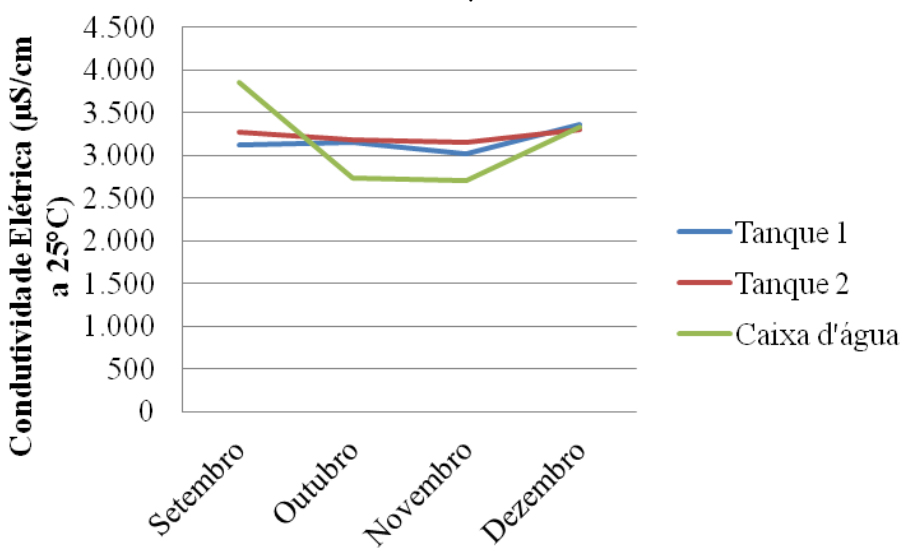

Figura 3. Condutividade elétrica da água cinza sem nenhum tratamento(caixa de água), no Tratamentos sem fitorremediação (Tanque 1) e com fitorremediação (Tanque 2).

Almeida (2010) menciona que quanto maior for o conteúdo salino de uma solução, maior será a Condutividade Elétrica da mesma. Portanto, a medida da Condutividade Elétrica é um indicador do perigo da salinidade do solo. No estudo de Ferreira (2013) efetuado na mesma lavanderia, o valor da condutividade elétrica elevou-se nos últimos meses de monitoramento o que corrobora com a presente pesquisa, provavelmente em resposta ao efeito da evapotranspiração da cultura que aumenta a concentração da solução do solo.

Conforme a Figura 4 os resultados de DQO obtiveram valores entre $49 \mathrm{mg} / \mathrm{L}$ a $618 \mathrm{mg} / \mathrm{L}$. O valor mínimo de $49 \mathrm{mg} / \mathrm{L}$ ocorreu apenas em novembro na caixa d'água (receptor do efluente) que obteve valor máximo de $483 \mathrm{mg} / \mathrm{L}$ em dezembro.

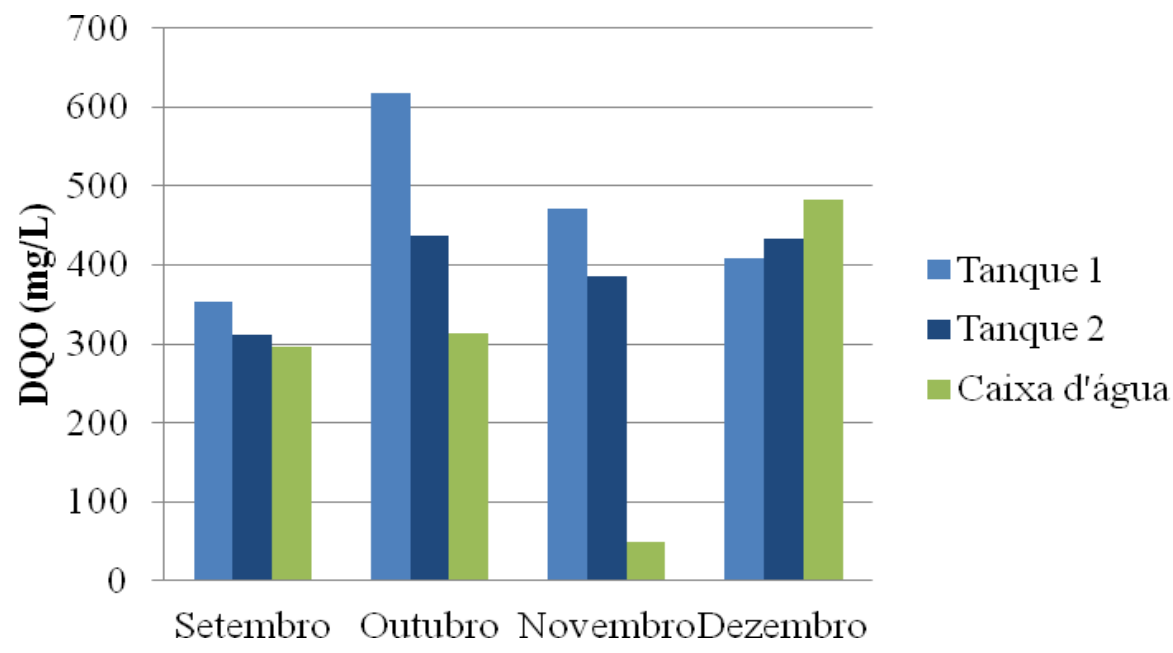

Figura 4. Demanda química de oxigênio da água cinza sem nenhum tratamento(caixa de água), no Tratamento sem fitorremediação (Tanque 1) e com fitorremediação (Tanque 2).

Na figura 4 a demanda química de oxigênio em relação aos tratamentos sem e com fitorremediação, o valor mínimo foi de $311 \mathrm{mg} / \mathrm{L}$ (setembro) e máximo de $438 \mathrm{mg} / \mathrm{L}$ (outubro) no tanque 2 em contrapartida no tanque 1 o valor mínimo foi de $354 \mathrm{mg} / \mathrm{L}$ (setembro) e máximo de $618 \mathrm{mg} / \mathrm{L}$ (outubro). Tais resultados revelam que os tanques obtiveram seus valores máximos e mínimos no mesmo período e os valores do tanque 1 foram continuamente mais elevados do que no tanque 2 com exceção do último mês. O tratamento com fitorremediação verifica-se (Figura 4) uma redução nos valores de DQO nos meses de setembro, outubro e novembro.

Alguns autores encontraram valores para DQO que variam de 158 a 522,3 mg/L (FRIEDLER et al., 2005; FIORI et al., 2006 e NIRENBERG \& REIS, 2010). Sendo assim, os valores encontrados nos tanques e na caixa d'água corroboram com a variação detectada na literatura apenas o valor máximo encontrado no tanque 1 em outubro e o valor mínimo detectado na caixa d'água em novembro foram diferentes.

Analisando a Figura 5 ficou evidente que os valores da caixa d'água obtiveram um pico no primeiro mês e assim decaindo com o passar do tempo enquanto que nos tanques o pico ocorreu no mês de novembro. As concentrações de fósforo em todas as amostras coletadas apresentaram valores acima do estabelecido pela resolução CONAMA 357 (BRASIL, 2005) para águas de classe 2, que seria de 0,05 $\mathrm{mg} / \mathrm{L}$. Porém, os resultados encontrados no presente estudo está entre os valores descritos por Nirenberg \& Reis (2010) $(1,3 \mathrm{mg} / \mathrm{L})$ e Fiori et al. $(2006)(0,84 \mathrm{mg} / \mathrm{L})$. 


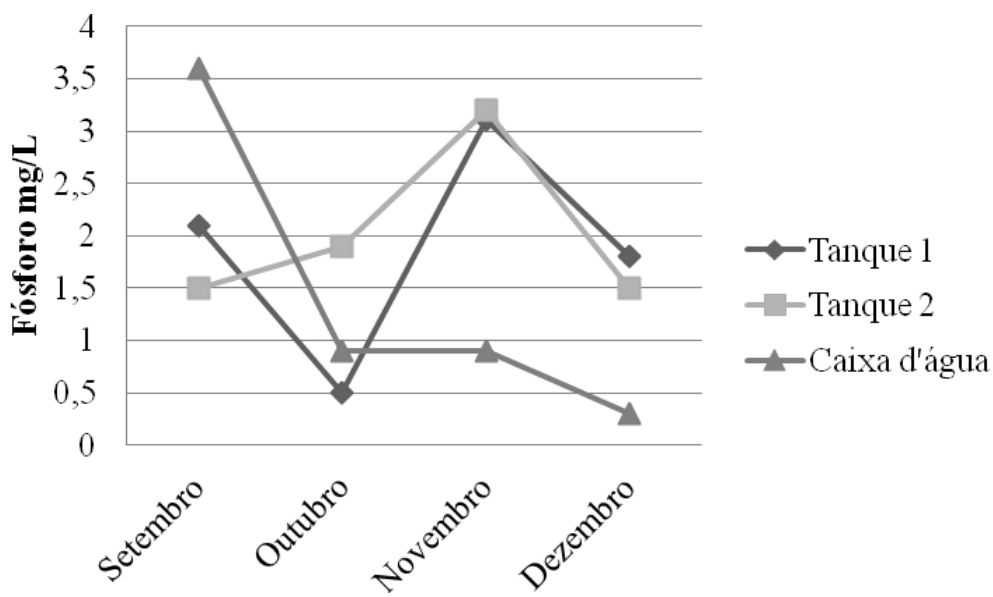

Figura 5. Fósforo total da água cinza sem nenhum tratamento(caixa de água), no Tratamento sem fitorremediação (Tanque 1) e com fitorremediação (Tanque 2).

Mota \& Von Speling (2009) afirmam que o fósforo é um nutriente essencial para o crescimento dos microrganismos responsáveis pela estabilização da matéria orgânica, além do fósforo não apresentar implicações sanitárias na qualidade da água. A quantidade de fósforo total deve-se ao uso de detergentes e saponáceos na lavagem das roupas de acordo com Athanásio (2010).

Segundo Van de Moortel et al. (2009), a liberação de oxigênio pelas raízes das plantas pode aumentar a capacidade de adsorção do fósforo por meio dos substratos, o que pode ter influenciado para fazer com que os sistemas de tratamento com plantas tivessem uma

eficiência de remoção maior do que os sistemas sem a presença das plantas.

De acordo com os parâmetros analisados verificou-se que a qualidade da água cinza tratada na unidade de produção agrícola controlada é eficaz ocorrendo redução da demanda química de oxigênio. $\mathrm{O}$ aumento do fósforo total nos tratamentos ocorre decorrente a ação anaeróbica do tratamento.

O tratamento de águas cinzas nas UPAC's é uma alternativa para o cultivo de forragens como também frutíferas, levando em consideração que á água utilizada na irrigação subsuperficial entra apenas em contato com as raízes e não com a parte superior da cultura.

\section{CONCLUSÃO}

A turbidez teve valores acima de 1.000 UNT. A demanda química de oxigênio, variou de de 311 a 438 mg/L com fitorremediação.

O tratamento com fitorremediação teve uma maior eficiência na redução de DQO.

A condutividade elétrica em ambos os tratamentos foi de 2.700 a $3.850 \mu \mathrm{S} / \mathrm{cm}$.

O tratamento com fitorremediação nas UPACs é eficaz e sustentável.

\section{REFERÊNCIAS BLIBLIOGRÁFICAS}

AESA - Agência Executiva de Gestão das Águas do Estado da Paraíba. SIGaesa-web. Disponível em: http://geo.aesa.pb.gov.br/. Acesso em: 10 de agosto de 2013.

ALMEIDA, O. A. Qualidade da água de irrigação [recurso eletrônico] / Otávio Álvares de Almeida. - Dados eletrônicos. - Cruz das Almas: Embrapa Mandioca e Fruticultura. 2010.

ANA. Agência Nacional de Águas. Conjuntura dos Recursos Hídricos no Brasil: informe 2011. Disponível em: < http://www2.ana.gov.br/Paginas/default.aspx>. Acesso em: 10 out. 2013.

ATHANÁSIO, A. C. Áreas urbanas contribuem para presença de fósforo nas águas. 2010. Disponivel em < http://www.saudeemmovimento.com.br/reportagem/not icia_frame.asp?cod_noticia $=3556>\quad$ Acesso em 09/07/2014.

AZEVEDO, D. C. F. Água: Importância e gestão no semiárido nordestino. Vol. 11, n.1, 2012.

BAIRD, C, CANN, M.Química Ambiental. 4 ed. Porto Alegre: Bookman, 2011.

BRASIL. Conselho Nacional de Meio Ambiente. Resolução $\mathrm{N}^{\circ} 397$, de 2008. Altera o inciso II do $\S 4 .^{\circ}$ e a Tabela X do $\S 5 .^{\circ}$, ambos do art. 34 da Resolução do Conselho Nacional do Meio Ambiente $\mathrm{N}^{\mathrm{o}}$ 357, de 2005, que dispõe sobre a classificação dos corpos de água e diretrizes ambientais para o seu enquadramento, bem como estabelece as condições e padrões de lançamento de efluentes. Resoluções vigentes publicadas entre julho de 1984 e novembro de 2008: 2. ed. Conselho Nacional do Meio Ambiente. Brasília, DF. 2008.

CEDRAZ, M. Gestão de recursos hídricos em regiões semiáridas. In: seminário cyted/ufba/ueps/srh-ba/mmasrh/fapex, 2002. 
ERIKSSON, E.; AUFFARTH, K.; MOGENS, H. LEDIN, A. Characteristics of grey wastewater. Urban Water, Dinamarca, v. 4, n.1, p. 58-104. 2002.

FERREIRA, A. C. Unidade de produção agrícola irrigada com águas cinzas de lavanderia pública no semiárido paraibano. Tese (Doutorado em Engenharia Agrícola) Universidade Federal de Campina Grande. Campina Grande. 2013.

FIORI, S.; FERNANDES, V. M. C.; PIZZO, H. Avaliação qualitativa e quantitativa do reuso de águas cinzas em edificações. Revista Ambiente Construído, Porto Alegre, v. 6, n. 1, p. 19-30. jan./mar. 2006.

FRIEDLER, E.; KOVALIO, R.; GALIL, N. I. On-site greywater treatment and reuse in multi-store buildings. Water Science \& Technology, Áustria, v. 51, n. 10, p. 187-194. 2005.

GALBIATI, A. F. Tratamento domiciliar de águas negras através de tanque de evapotranspiração. $38 \mathrm{f}$. Dissertação (Mestrado em Tecnologias Ambientais) Universidade Federal de Mato Grosso do Sul. Campo Grande. 2009.

HARTMANN, PHILIPP. A cobrança pelo uso da água como instrumento econômico na política ambiental: estudo comparativo e avaliação econômica dos modelos de cobrança pelo uso da água bruta propostos e implementados no Brasil. Porto Alegre: AEBA, 2010.

LOPES, B. A. O capim elefante. Universidade Federal de Viçosa, Centro de Ciências Agrárias, Departamento de Zootecnia. Seminário apresentado à disciplina ZOO 645 (Métodos nutricionais e alimentação de ruminantes). Viçosa. 2004.

MOTA, F. S. B.; VON SPELING, M. Nutrientes de esgoto sanitário: utilização e remoção. Rio de Janeiro: ABES, 2009. ISBN: 978-85-7022-164-3

NIRENBERG, L.P.; REIS, R. P. A. Avaliação do desempenho de sistema de reuso de água de uma edificação unifamiliar em Goiânia-Go. REEC Revista Eletrônica de Engenharia Civil, UFG, n. 1, p. 1-10. 2010. Disponível em: <http://www.revistas.ufg.br/index.php/reec/index>. Acesso em 15/09/2013.

NIRENBERG, L.P.; REIS, R. P. A. Avaliação do desempenho de sistema de reuso de água de uma edificação unifamiliar em Goiânia-Go. REEC Revista Eletrônica de Engenharia Civil, UFG, n. 1, p. 1-10. 2010. Disponível em: <http://www.revistas.ufg.br/index.php/reec/index>. Acesso em 15/09/2013.

PILON-SMITS, E. Phytoremediation. Annu. Rev. Plant Biol. 2005.

REBOUÇAS, A. da C.; BRAGA, B.; TUNDISI, J. G. (Ed.). Águas doces no Brasil: capital ecológico, uso e conservação. São Paulo: USP/ABC, Escrituras Editoras, 1999. Cap. 2, p. 39- 62.

SALATI, E.; LEMOS, H. M. Água e o desenvolvimento sustentável. In: INTERNACIONAL CYTED-XVII, 2002, Salvador, BA. Resumos. Salvador.

SANDRI, D.; MATSURA, E. E.; TESTEZLAF, R. Desenvolvimento da alface Elisa em diferentes sistemas de irrigação com água residuária. Revista Brasileira de Engenharia Agrícola e Ambiental, Campina Grande, v. 11, n. 1, 2007. 17-29p.Disponível em: www.epublicações.uerj.br. Acesso em 31\10\2013.

VAN DE MOORTEL, A. M. K.; ROUSSEAU, D. P. L.; TACK, F. M. G.; PAUW, N. D. A comparative study of surface and subsurface flow constructed wetlands for treatment of combined sewer overflows: a greenhouse experiment. Ecological Engineering, v. 35, n. 2, p. 175183 , 2009. http://dx.doi.org/10.1016/j.ecoleng.2008.08.015 